\title{
Examining Individual Demographic and School Support Factors Regarding Teachers' Intention to Use Technology: A Hierarchical Regression Analysis
}

\author{
https://doi.org/10.3991/ijet.v16i12.22625 \\ Miaoqi Huang \\ Dalian Polytechnic University, Dalian, P.R. China \\ Li Xiangming $(\bowtie)$ \\ Tsinghua University, Beijing, P.R. China \\ lixmesz.tsinghua.edu.cn \\ Jingshun Zhang \\ Florida Gulf Coast University, Fort Myers, USA
}

\begin{abstract}
A proliferation of literature documented the correlation between the teachers' use of technology and the factors of technostress, burnout as well as the pedagogical content knowledge. Yet insufficient findings explored the impacting factors of demographic factors of individual teachers and school support on educational use of technology. Hierarchical regression employed in this study advanced the traditional regression analysis of individual demographic factors, added by the second-step of school support model. The statistical results supported both hypotheses that model 1 of individual factors and model 2 of the combined factors of individual and school support significantly predicted teachers' use of technology. In addition, the study results showed that R square value progressed from 0.26 in model 1 to 0.60 in model 2 , implying the additional $34 \%$ of the variance explained by the combined factors collectively. The findings shed lights on the robustness of the models in predicting teachers' intention to use technology and the school administrative policy in advocating the persistent use of ICT in educational settings.
\end{abstract}

Keywords - Hierarchical Regression Analysis; Individual Demographic Variables; Intention to Use Technology; School Support

\section{$1 \quad$ Introduction and Literature Review}

Teachers' intention to use technology refers to the degree that individual teachers are willing to accept and adopt the technological tools in purely online or blended context of teaching $[1,2]$. A plethora of scholarly works has contributed to the impacting factors of technostress, burnout and the pedagogical content knowledge on teachers' intention to use technology [3]. Yet insufficient findings explored the demographic variables of individual teachers and school support on educational use of 
technology. Even, very few prior studies attempted to employ hierarchical regression in analyzing both factors of individual and school support. Compared with the traditional regression estimates, hierarchical regression highlighted the change of $\mathrm{R}^{2}$ as the indicator of various contributing degrees of independent variables to the dependent variable [4].

School support in this study is defined as the endeavor school administration engaged in on providing technical support, infrastructure, supporting policies and training program for teachers and other stakeholders [5, 6]. Preliminary studies have proved that school infrastructure had major impacts on teaching, which included the resource allocations, information technology and network equipment and hardware [7, 8]. In addition, previous study also revealed that school policy promoted the technology use in educational settings [9]. Joo (2019) [10] placed the concept of school support into three categories including institutional support and policies, technical support and infrastructure, social support and collaborations among colleagues. The study revealed the significant correlation between school support and teachers' willingness to use technology.

Scholars also devoted their efforts to the study of correlation between inadequate school system and technical stress on teachers. The findings showed that teachers were likely to experience the pressure in using technology when the school system failed to provide supportive measures. The stress of using technology led to insufficiency in course preparation time and incompatibility with the existing curriculum. Substantial evidence supported the claim that lack of school support became the debilitating factors in using technology for educational purpose [11,12,13].

\section{Research Hypotheses}

In order to predict teachers' intention to use technology, this study attempted to examine both individual- and school-level factors which were less represented in previous literature. Individual demographic variables include gender, age, professional title, major and prior experience of technology use, while school support covers 9 factorial items. Hierarchical regression was employed in the study signaling varying degrees of contribution by both factors. Therefore, two hypotheses were proposed in this paper.

- Hypothesis 1: Model 1 of teachers' individual demographic factors predicts the teachers' intention to use technology.

- Hypothesis 2: Model 2 of individual demographic factors added by school supporting factors predicts the teachers' intention to use technology with greater explanatory power. 


\section{$3 \quad$ Methodology}

\subsection{Participants}

Questionnaires were distributed to college teachers from P. R. China nationwide, mostly in northeast, north, south, east and northwest part of China. Male and female respondents accounted for $24.53 \%$ and $75.47 \%$ respectively; The majority of respondents were under 49 years old; Those with professional titles of associate professors or above accounted for $54.72 \%$; Those with science and engineering background account for about $60 \%$; Almost $88.69 \%$ of the respondents reported previous experience of using technology, as shown in Table 1 below.

Table 1. Demographic Information of Respondents (N-106)

\begin{tabular}{|c|l|c|c|c|}
\hline Variable & \multicolumn{1}{|c|}{ Category } & Number & Percentage (\%) & Cumulative (\%) \\
\hline \multirow{2}{*}{ Gender } & Male & 26 & 24.53 & 24.53 \\
\cline { 2 - 5 } & Female & 80 & 75.47 & 100.00 \\
\hline \multirow{3}{*}{ Age } & Below 39 & 40 & 37.74 & 37.74 \\
\cline { 2 - 5 } & $40-49$ & 48 & 45.28 & 83.02 \\
\cline { 2 - 5 } & 50 and Above & 18 & 16.98 & 100.00 \\
\hline \multirow{3}{*}{ Prof. Title } & Assistant Prof. & 42 & 39.61 & 39.61 \\
\cline { 2 - 5 } & Assistant and Full Prof. & 58 & 54.72 & 94.34 \\
\cline { 2 - 5 } & Others & 6 & 5.66 & 100.00 \\
\hline \multirow{2}{*}{ Major } & Science \& Engineering & 63 & 59.43 & 59.43 \\
\cline { 2 - 5 } & A\&H and Social Science & 43 & 40.57 & 100.00 \\
\hline \multirow{2}{*}{ Prior Exp. } & $Y$ & 12 & 88.69 & 88.68 \\
\cline { 2 - 5 } & $\mathrm{N}$ & 11.32 & 100.00 \\
\hline
\end{tabular}

Notes: Prof. Title=Professional Title; Prior Exp.=Previous experience of using technology in educational settings

\subsection{Instruments}

Besides demographic information questionnaire, the scales of perceived school support and intent to use technology in the future used in this study were selected and adapted from the doctoral dissertation by Cai (2019) [14].

Demographic information questionnaire: The demographic information questionnaire collected the participants' personal data including gender, age, professional title, major and their prior experience of using technology.

Perceived Organizational Support (POS): Placed on a 5-point Likert scale ranging from 1 (Strongly Disagree) to 5 (Strongly Agree), this scale contains 9 items about supporting roles of school administration on teachers' use of technical tools.

Teachers' Intent to Use Technology (TIUT): The scale covers one single item "I would like to use technological tools in online or blended teaching in my current and future teaching plans" ranging from 1 (Strongly Disagree) to 5 (Strongly Agree). 
Descriptive analysis results of both scales of POS and TIUT are displayed in Table 2 below. The reliability analysis of POS showed that the Cronbach coefficient is 0.96 , indicating a high internal consistency.

Table 2. Descriptive analysis of both scales

\begin{tabular}{|c|c|c|c|c|c|}
\hline \multicolumn{6}{|c|}{ Scale 1 Perceived School Support, 9 items, Cronbach $\alpha=0.96$} \\
\hline & Items & Min & $\operatorname{Max}$ & Mean & $S D$ \\
\hline 1 & Share Values & 1 & 5 & 4.34 & .97 \\
\hline 2 & Offer Help & 1 & 5 & 4.28 & .87 \\
\hline 3 & Care for well-beings & 1 & 5 & 4.52 & .72 \\
\hline 4 & Help Bring Full Potential & 1 & 5 & 4.57 & .69 \\
\hline 5 & Be Proud of Achievement & 1 & 5 & 4.55 & .76 \\
\hline 6 & Training Workshop & 1 & 5 & 4.49 & .84 \\
\hline 7 & Training Schedule & 1 & 5 & 4.50 & .77 \\
\hline 8 & Take Advice & 1 & 5 & 4.50 & .75 \\
\hline 9 & Show Respect & 1 & 5 & 4.54 & .75 \\
\hline \multicolumn{6}{|c|}{ Scale 2 Teachers' Intent to Use Technology, 1 item } \\
\hline & Items & Min & $\operatorname{Max}$ & Mean & $S D$ \\
\hline $\begin{array}{l}\text { I wo } \\
\text { blen } \\
\text { plan }\end{array}$ & $\begin{array}{l}\mathrm{d} \text { like to use technological tools in online or } \\
\mathrm{d} \text { teaching in my current and future teaching }\end{array}$ & 1 & 5 & 4.46 & .80 \\
\hline
\end{tabular}

\subsection{Data analysis}

The QR code of the online questionnaire was generated and distributed to respondents nationwide for convenience sampling. A total number of 106 out of 120 respondents filled the questionnaire at the response rate of $88 \%$.

The data were examined in descriptive statistics and hierarchical regression analysis with the data processing program SPSSAU20.0 [15].

\section{$4 \quad$ Results}

In this study, hierarchical regression was conducted to determine whether both factors of individual demographic information and school support predicted teachers' intention to use technology. As displayed in Table 3 below, the hierarchical regression analysis involved two models. The first model (Model 1) covered independent variables of gender, age, professional title, major and previous experience of using technology in education. In the following step (Model 2), newly added were the school support factors including sharing values; offering help; caring for well-beings; helping bring full potential; being proud of achievement; providing training workshop with flexible training time schedule; taking advice from and showing respect to teachers. The dependent variable in the model referred to teachers' intention to use technology in educational settings. 
Table 3. Hierarchical regression analysis in two models $(n=106)$

\begin{tabular}{|c|c|c|c|c|c|c|c|c|}
\hline \multicolumn{5}{|c|}{ Model 1} & \multicolumn{4}{|c|}{ Model 2} \\
\hline & $\boldsymbol{B}$ & Std. Error & $t$ & $p$ & $\boldsymbol{B}$ & Std. Error & $t$ & $p$ \\
\hline Constant & 5.46 & 0.49 & 11.06 & 0.000 & $3.20 * *$ & 0.61 & 5.26 & 0.000 \\
\hline \multicolumn{9}{|l|}{ Demographic } \\
\hline Gender & 0.03 & 0.17 & 0.15 & 0.88 & -0.10 & 0.14 & -0.73 & 0.47 \\
\hline Age & - & 0.09 & -1.22 & 0.23 & -0.11 & 0.07 & -1.54 & 0.13 \\
\hline Prof. Title & 0.20 & 0.07 & 2.79 & 0.006 & $0.13 *$ & 0.06 & 2.11 & 0.04 \\
\hline Major & 0.05 & 0.06 & 0.85 & 0.40 & 0.05 & 0.04 & 1012 & 0.26 \\
\hline Prior Exp. & & 0.23 & -5.80 & 0.000 & $-0.77 * *$ & 0.20 & -3.88 & 0.000 \\
\hline \multicolumn{9}{|l|}{ School Support } \\
\hline Share Values & & & & & 0.17 & 0.010 & 1.70 & 0.09 \\
\hline Offer Help & & & & & -0.08 & 0.09 & -0.87 & 0.39 \\
\hline Care for well-beings & & & & & -0.12 & 0.15 & -0.82 & 0.42 \\
\hline Help Bring Full Potential & & & & & -0.16 & 0.19 & -0.88 & 0.38 \\
\hline Be Proud of Achievement & & & & & 0.17 & 0.21 & 0.81 & 0.42 \\
\hline Training Workshop & & & & & $0.61 * *$ & 0.16 & 3.81 & 0.000 \\
\hline Training Schedule & & & & & -0.04 & 0.18 & -0.25 & 0.80 \\
\hline Take Advice & & & & & -0.38 & 0.29 & -1.29 & 0.20 \\
\hline Show Respect & & & & & 0.31 & 0.30 & 1.04 & \\
\hline \multicolumn{9}{|l|}{0.30} \\
\hline $\mathrm{R}^{2}$ & & & 0.26 & & & 0.60 & & \\
\hline Adj R² & & & 0.23 & & & \begin{tabular}{l|l}
0.53 & \\
\end{tabular} & & \\
\hline F Value & & \multicolumn{3}{|c|}{$\mathrm{F}(5,100)=7.19, \mathrm{p}=0.000^{* * *}$} & & \multicolumn{3}{|c|}{$\begin{array}{c}\mathrm{F}(14,91)=9.59 \\
\mathrm{p}=0.000 * * *\end{array}$} \\
\hline$\Delta \mathrm{R}^{2}$ & & & 0.26 & & & \begin{tabular}{l|l}
0.34 & \\
\end{tabular} & & \\
\hline$\Delta \mathrm{F}$ Value & & \multicolumn{3}{|c|}{$\mathrm{F}(5,100)=7.19, \mathrm{p}=0.000^{* * * *}$} & & \multicolumn{3}{|c|}{$\mathrm{F}(9,91)=8.30, \mathrm{p}=0.000^{* * *}$} \\
\hline
\end{tabular}

Dependent Variable: Teachers' Intention to Use Technology $* \mathrm{p}<0.05 ; * * * \mathrm{p}<0.001$

$\mathrm{F}$ test $(\mathrm{F}=7.19, \mathrm{P}=0.000<0.001)$ in Model 1 showed that the teachers' individual demographic variables of gender, age, professional title, major and prior experience significantly predicted teachers' intention to use technology in the future. R-square value in Model 1 was 0.26 , implying that the combined variables of gender, age, professional title, major and prior experience explained $26 \%$ of the variance in predicting teachers' intention to use technology in online or blended educational contexts. Specifically, the single variable of professional title in Model 1 showed the significantly positive correlation with teachers' intention to use technology $(\mathrm{t}=2.79, \mathrm{P}=0.006<$ $0.01)$, while the variable of prior experience featured the negative correlation $(\mathrm{t}=$ 5.80, $\mathrm{P}=0.000<0.001)$.

In Model $2, \mathrm{~F}$ test $(\mathrm{F}=9.59, \mathrm{P}=0.000<0.001)$ yielded the results that the school support factors added on the teachers' individual demographic variables also significantly predicted teachers' intention to use technology in the future. Model 2 generated $\mathrm{R}$ square value of 0.60 in contrast with the value of 0.26 in Model 1 . The changes of 
$\mathrm{R}$ square value showed an increasing trend and resulted in additional contribution of $34 \%$ to the overall explained variance in Model 2.

The overall results in model comparison are displayed as follows:

Model 1: Teachers' Intention to Use Technology $=$ Constant + Gender + Age Range + Professional Title + Major + Prior Experience $\left(\mathrm{R}^{2}=.26 ; \mathrm{F}=7.19 ; \mathrm{P}=0.000<\right.$ $0.001)$ )

Model 2: Teachers' Intention to Use Technology $=$ Constant + Gender + Age Range + Professional Title + Major + Prior Experience + \# of School Support 1-9 items $\left(\mathrm{R}^{2}=.60 ; \mathrm{F}=9.59 ; \mathrm{P}=0.000<0.001\right)$

Statistical results showed that both models significantly predicted teachers' intention to use technology. Further, Model 2 explained the dependent variable better than did Model 1. The newly added factor of school support explained an additional $34 \%$ of the variance in predicting the use of technology.

\section{Discussion}

\subsection{Predictive factors of teachers' intention to use technology}

In response to Hypothesis 1 , the hierarchical regression analysis results proved that teachers' individual demographic characteristics predicted teachers' technology use. While previous studies mainly focused on the relationship between individual demographic factors of teachers and techno stress [16], the findings of Model 1 added to the existing body of research by extending the individual factors to teachers' intention to use technology.

In response to Hypothesis 2, the combined individual and school support factors also predicted teacher's intention to use technology. This finding corroborated prior studies about the correlation between school support and teachers' technology use [17]. Further, this study advanced to the framework for model comparison by adding school support variables to Model 1 . The study results determined that the newly added variables of school support showed a significant progress in the percentage of the explained variance in teachers' intention to use technology.

\subsection{Implications for teachers' professional development and school policymaking}

Positive correlation was generated in this study between the teachers' professional title and intention to use technology. It can be explained that college teachers on early career stage are likely to engage in research and paper publications which are essential for faculty promotion. The technology-enhanced teaching innovation requires considerable time and efforts. Risk aversion avoids large number of consumptions in technology use in teaching activities.

Also, prior experience of technology use was negatively correlated with their subsequent intention. The finding indicated that teachers with previous experience are willing to maintain or continue the existing teaching mode. 
The variable of school-supported training and workshop was positively correlated with teachers' intention to use technology. The study results are in line with scholars' proposal of providing advanced training activities and classroom integration of information technology [18], starting with pedagogical and teaching theory, followed by "theory + practice" training mode [19].

\section{Conclusion}

By performing hierarchical regression analysis, this study examined and confirmed the research hypotheses that the variables of individual demographic features and school support predicted teachers' intention to use technology. The study further determined both variables in explaining the statistically significant amount of variance. The variable of school support newly added on the individual demographic factors strengthened the explained variance by a significant percentage of $34 \%$.

The limits lie in two aspects though. First, we have to take caution while attempting to apply the conclusive findings to the population nationwide. The convenience sampling prevents from generalizing the conclusions across the country. Second, this study did not incorporate the factors of techno stress or burnout in the existing literature works. Their incorporation with the two variables in this study and their impact on teachers' intention to use technology are yet to explore.

Future research efforts could direct to student group on their intention to use technology in learning activities for comparison with teacher counterpart. Also, researchers could build the model in predicting the intention to use technology by adding additional variables of cognitive loading and emotional factors.

\section{$7 \quad$ Acknowledgement}

The present study was supported by Overseas Joint Research Grant, Shenzhen International Graduate School, Tsinghua University (HW2020003) and Guangdong Basic and Applied Basic Research Foundation (2021A1515012563).

\section{$8 \quad$ References}

[1] Teo, T. (2011). Factors influencing teachers' intention to use technology: Model development and test. Computers \& Education, 57 (4), 2432-2440. https://doi.org/10.1016/j. compedu.2011.06.008

[2] Kashada, A., Li, H., \& Koshadah, O. (2018). Analysis Approach to Identify Factors Influencing Digital Learning Technology Adoption and Utilization in Developing Countries. International Journal of Emerging Technologies in Learning, 15(18), 165-182. https://doi.org/10.3991/ijet.v13i02.7399

[3] Panisoara, I. O., Lazar, I., Panisoara, G., Chirca, R., \& Ursu, A. S. (2020). Motivation and Continuance Intention towards Online Instruction among Teachers during the COVID-19 Pandemic: The Mediating Effect of Burnout and Technostress. International Journal of 
Environmental Research and Public Health, 17(21), 8002. https://doi.org/10.3390/ijerph 17218002

[4] Chen, Y., Wang, J., \& Yu, Y. (2019). A Study on Consumers' Willingness to Pay for Remanufactured Products: A Study Based on Hierarchical Regression Method. Frontiers in Psychology. 10:2044. https://doi.org/10.3389/fpsyg.2019.02044

[5] Eickelmann, B., Gerick, J., \& Koop, C. (2017). ICT use in mathematics lessons and the mathematics achievement of secondary school students by international comparison: Which role do school level factors play? Education and Information Technologies, 22, 125. https://doi.org/10.1007/s10639-016-9498-5

[6] Porter, W. W., \& Graham, C. R. (2016). Institutional drivers and barriers to faculty adoption of blended learning in higher education. British Journal of Educational Technology, 47(4), 748-762. https://doi.org/10.1111/bjet.12269

[7] Albirini, A. (2006). Teachers' attitudes toward information and communication technologies: the case of Syrian EFL teachers. Computers \& Education, 47, 373-398. https://doi.org/10.1016/j.compedu.2004.10.013

[8] Jones, D. V. (2004). National numeracy initiatives in England and Wales: parallel attempts at achieving largescale reform. Compare, 34, 463-486. https://doi.org/10.1080/ $\underline{0305792042000294832}$

[9] Tondeur, J., Valcke, M., \& Braak, J. V. (2008). A Multidimensional Approach to Determinants of Computer Use in Primary Education: Teacher and School Characteristics. Journal of Computer Assisted Learning, 24(6), 494-506. https://doi.org/10.1111/j.13652729.2008.00285.X

[10] Joo, Y.J.; Lim, K.Y.; Kim, N.H. (2016) The effects of secondary teachers' technostress on the intention to use technology in South Korea. Comput. Educ. 95, 114-122. https://doi.org/10.1016/j.compedu.2015.12.004

[11] Teo, T., \& van Schaik, P. (2012). Understanding the Intention to Use Technology by Preservice Teachers: An Empirical Test of Competing Theoretical Models. International Journal of Human-Computer Interaction, 28(3), 178-188. https://doi.org/10.1080/104 47318.2011.581892

[12] Drossel, K., Eickelmann, B., \& Gerick, J. (2016). Predictors of teachers' use of ICT in school - the relevance of school characteristics, teachers' attitudes and teacher collaboration. Education and Information Technologies, 22(2), 551-573. https://doi.org/10.1007/s 10639-016-9476-y

[13] Bøe, T., Gulbrandsen, B., \& Sørebø, Ø. (2015). How to stimulate the continued use of ICT in higher education: Integrating Information Systems Continuance Theory and agency theory. Computers in Human Behavior, 50, 375-384.https://doi.org/10.1016/j.chb.2015.03. $\underline{084}$

[14] Cai, J. (2019). Understanding the Adoption and Continuous Use of Flipped Classroom by Instructors and Students from the Perspective of Teaching System. Ph.D. Dissertation, Central China Normal University.

[15] The SPSSAU project (2020). SPSSAU (Version 20.0) [Online Application Software]. Retrieved from https://www.spssau.com.

[16] Özgür, H. (2020). Relationships between teachers' technostress, technological pedagogical content knowledge (TPACK), school support and demographic variables: A structural equation modeling. Computers in Human Behavior, 106468. https://doi.org/10.1016/ j.chb. 2020.106468

[17] Syvänen,A., Mäkiniemi, J.P., Syrjä, S., Heikkilä-Tammi, K. \& Viteli, J. (2016). When does the educational use of ICT become a source of technostress for Finnish teachers? International journal of media, technology and lifelong learning, 12 (2), 95-109. 
[18] Eickelmann, B. (2011). Supportive and hindering factors to a sustainable implementation of ICT in schools. Journal for Educational Research Online/Journal für Bildungsforschung Online, 3(1), 75-103.

[19] Law, N. \& Chow, A. (2008). Teacher characteristics, contextual factors, and how these affect the pedagogical use of ICT. In N. Law, W. J. Pelgrum \& T. Plomp (Eds.), Pedagogy and ICT Use in Schools around the World. Findings from the IEA SITES 2006 Study (CERC Studies in Comparative Education, Vol. 23, pp. 181-219). Hong Kong: CERCSpringer. https://doi.org/10.1007/978-1-4020-8928-2

\section{$9 \quad$ Authors}

Miaoqi Huang is an Assistant Researcher in Human Resources Department of Dalian Polytechnic University, P.R. China. Her research area focuses on the study of faculty professional development and school support policy in tertiary settings. Her Email: huangmq@dlpu.edu.cn.

Li Xiangming is an Associate Professor in Shenzhen International Graduate School, Tsinghua University, P. R. China. Her research interests include mobile learning and instructional design in higher educational settings, and EFL teaching. Her Email: lixm@sz.tsinghua.edu.cn.

Jingshun Zhang is an Associate Professor in College of Education, Florida Gulf Coast University, USA. His research interests mainly include classroom assessment, research methodology and cognitive diagnostic assessment. His email: jzhang@fgcu.edu.

Article submitted 2021-03-13. Resubmitted 2021-04-19. Final acceptance 2021-04-20. Final version published as submitted by the authors. 